\title{
Neuroimaging studies of striatum in cognition part II: Parkinson's disease
}

\author{
Alexandru Hanganu 1,2,3†, Jean-Sebastien Provost ${ }^{3,4}$ and Oury Monchi ${ }^{1,2,3 * \dagger}$ \\ ${ }^{1}$ Department of Clinical Neurosciences and Department of Radiology, Cumming School of Medicine, University of Calgary, \\ Calgary, AB, Canada, ${ }^{2}$ Hotchkiss Brain Institute, University of Calgary, Calgary, AB, Canada, ${ }^{3}$ Centre de Recherche de \\ I'Institut Universitaire de Gériatrie de Montréal, Université de Montréal, Montréal, QC, Canada, ${ }^{4}$ Department of Psychology, \\ Faculty of Arts and Sciences, University of Montreal, Montreal, QC, Canada
}

OPEN ACCESS

Edited by:

Lili-Naz Hazrati,

University of Toronto, Canada

Reviewed by:

Fahad Sultan

University Tübingen, Germany

Krystal Lynn Parker,

University of lowa, USA

Iman Kamali Sarvestani,

University of Toronto, Canada

*Correspondence:

Oury Monchi

Health Science Center, Hotchkiss Brain Institute, University of Calgary, Room 2915, 3330 Hospital DR NW,

Calgary T2N 1N4, AB, Canada oury.monchi@ucalgary.ca

${ }^{\dagger}$ These authors have contributed equally to this manuscript

Received: 05 May 2015 Accepted: 22 September 2015 Published: 08 October 2015

Citation:

Hanganu A, Provost J-S and

Monchi O (2015) Neuroimaging studies of striatum in cognition part II: Parkinson's disease.

Front. Syst. Neurosci. 9:138. doi: 10.3389/fnsys.2015.00138
In recent years a gradual shift in the definition of Parkinson's disease (PD) has been established, from a classical akinetic-rigid movement disorder to a multi-system neurodegenerative disease. While the pathophysiology of PD is complex and goes much beyond the nigro-striatal degeneration, the striatum has been shown to be responsible for many cognitive functions. Patients with PD develop impairments in multiple cognitive domains and the PD model is probably the most extensively studied regarding striatum dysfunction and its influence on cognition. Up to $40 \%$ of PD patients present cognitive impairment even in the early stages of disease development. Thus, understanding the key patterns of striatum and connecting regions' influence on cognition will help develop more specific approaches to alleviate cognitive impairment and slow down its decline. This review focuses on the contribution of neuroimaging studies in understanding how striatum impairment affects cognition in PD.

Keywords: striatum, cognition, Parkinson's disease, neuroimaging, dopamine

\section{Introduction}

Parkinson's disease (PD) is a progressive neurodegenerative disorder that affects up to $2 \%$ of individuals aged 65 years and older (Rijk et al., 1997) and has an incidence of 14 per 100,000 individuals (Hirtz et al., 2007). In people over 70 years the incidence is much higher-160 per 100,000 individuals (Hirtz et al., 2007), and affects nearly $10 \%$ of people older than 80 years (von Campenhausen et al., 2005). Furthermore, the prevalence of PD is expected to double by 2030 (Dorsey et al., 2007). While PD is associated with a complex pathophysiology that can potentially affect most of the brain, the motor cardinal symptoms of PD are largely due to degeneration of dopamine (DA) neurons in the substantia nigra pars compacta (Albin et al., 1989). This pattern of neurodegeneration starts from dorsal striatum and extends to more ventral parts of the striatum as the disease progresses (Kish et al., 1988).

Since the second part of the 1980's it is becoming increasingly clear that cognitive deficits can be present even at the early stages of PD (Taylor et al., 1986; Taylor and Saint-Cyr, 1995; Dubois and Pillon, 1996). Initial investigations in mild to moderately affected PD patients emphasized deficits in executive functions (e.g., planning and set-shifting), which resemble those found in patients with frontal lobe damage (Taylor et al., 1986; Owen et al., 1990, 1992). These are consistent with the fronto-striatal dysfunction occurring in PD reported by our group and many others. However, non-frontal cognitive deficits including visuospatial and language function difficulties are also recognized in early-PD patients and at various stages of disease progression. In the context of this review we concentrate on the cognitive deficits that are most likely to originate from the 
fronto-striatal deficits. Indeed, striatal dysfunction in the context of cognitive deficits in PD is likely the most extensively studied amongst neurological and mental disorders affecting striatal functions.

Individuals who meet criteria for mild cognitive impairment (MCI) exhibit measurable cognitive deficits but those deficits are not severe enough to interfere significantly with daily life, nor reach criteria for dementia. MCI in PD patients can be identified using the MDS Task Force criteria (Litvan et al., 2012) and can be found in the early stages of the disease with up to $65 \%$ of patients at 1 standard deviation below normative values and in up to $42 \%$ of PD patients at 1.5 standard deviation (Aarsland and Kurz, 2010; Yarnall et al., 2014). Furthermore, PD patients with MCI have a higher risk of developing dementia compared with patients who do not have MCI (Emre et al., 2007; Kehagia et al., 2010).

Changes in dopaminergic availability are known to greatly affect fronto-striatal function in $\mathrm{PD}$ and to affect cognitive processes (Cools, 2006). Furthermore, dopaminergic therapy aimed at the motor symptoms of PD is likely to have an influence on cognition in PD. In this review we focus on how striatum and related dopamine dysfunction can affect cognition in $\mathrm{PD}$ and how dopaminergic medication can modulate those functions.

\section{Striatum Organization}

In humans, striatum is attributed to a complex consisting of the caudate nucleus and putamen (dorsal striatum) as well as the most ventral part of the caudate nucleus, the ventral part of the putamen and the nucleus accumbens (ventral striatum) (Grahn et al., 2009). The striatum connections are organized into direct and indirect pathways which are based on the striatal output projections (Figure 1) (Albin et al., 1989). The nigral neurons project via the nigrostriatal pathway to the striatum (Samii et al., 2004) and provide dopamine (DA), which reinforces cortically initiated activation of a particular basal ganglia-thalamo-cortical circuit. This is achieved by facilitating conduction through the circuit's direct pathway, which has a net excitatory effect on the thalamus, and suppressing conduction through the indirect pathway, which has a net inhibitory effect on the thalamus (Alexander and Crutcher, 1990).

The direct pathway consists of neurons that predominantly express D1 DA receptors, substance P and dynorphin (Haber and Nauta, 1983; Gerfen et al., 1990; Steiner and Gerfen, 1999). They project from the striatum to the internal segment of the globus pallidus (GPi) and to substantia nigra pars reticulata $(\mathrm{SNr})$, eliciting a phasic inhibition of the $\mathrm{GPi} / \mathrm{SNr}$ and promoting desired movements (Alexander et al., 1986). The indirect pathway on the other hand, is comprised of striatal neurons that express predominantly D2 receptors (Gerfen et al., 1990), met-enkephalin and neurotensin (Haber and Nauta, 1983; Steiner and Gerfen, 1999). These neurons project to external portion of the globus pallidus (GPe) and the subthalamic nucleus (STN). Since GPe tonically inhibits the SNr, activation of the indirect pathway performs an inhibition of the GPe and a disinhibition of the SNr resulting in increased inhibitory activity of the $\mathrm{SNr}$ over the thalamus and thus exerting an inhibition or termination of the movement (Alexander et al., 1986). DA is a modulatory neurotransmitter and mediates synaptic plasticity both morphologically (Li et al., 2004) and electrophysiologically (Calabresi et al., 1992; Reynolds et al., 2001). The phasic activation of DA-ergic neurons exert a net excitatory effect on the direct pathway and an inhibitory effect on the indirect pathway (Delong and Wichmann, 2007), thus facilitating or inhibiting the functions that depend on striatum activitymovements, learning, working memory, attention, and other. The hyperdirect pathway originates from the axon collaterals of pyramidal tract neurons and project to the STN, thus it receives and displays activity directly related to movement (Giuffrida et al., 1985). This path is faster than the direct and indirect pathways and it exerts a powerful excitatory effects on the STN further activating GPi neurons and resulting in the inhibition of large areas of the thalamus and cortex that are related to the selected movements and or competing programs (Nambu et al., 2002).

Striatum connectivity with the cortex has been initially studied in monkeys and later on using magnetic resonance diffusion tensor imaging in humans, in vivo (Lehéricy et al., 2004). The head of the caudate and the rostral putamen were shown to be connected primarily to the frontal lobe (medial, ventral, dorsolateral prefrontal cortex (PFC), frontal pole, pre-supplementary motor area); the posterior putamen revealed anatomical connectivity with posterior supplementary motor area, motor and sensory areas, while the ventral striatum was connected to orbitomedial frontal cortex, temporal pole, amygdala, and hippocampus (Lehéricy et al., 2004). This connectivity pattern is in line with previously described frontostriatal circuits which were segregated into "motor" (supplementary motor area $\rightarrow$ putamen), "limbic" (anterior cingulate $\rightarrow$ nucleus accumbens), and "associative" domains, specifically the oculomotor loop (frontal eye fields $\rightarrow$ caudate nucleus), the dorsolateral circuit (dorsolateral prefrontal cortex $\rightarrow$ dorsolateral caudate nucleus), and ventral orbital loop (orbitofrontal cortex $\rightarrow$ ventromedial caudate nucleus) (Alexander et al., 1986, 1989).

In $\mathrm{PD}$, the loss of $\mathrm{DA}$-ergic inputs from substantia nigra pars compacta $(\mathrm{SNc})$ leads to an enhanced cholinergic signaling that in turn produces disinhibition of D2-receptor-containing striatum neurons. Both the glutamatergic inputs from the cortex to the striatum and from the STN to the output nuclei are significantly enhanced while the GABA-ergic inputs from the striatum and the external segment of the pallidum to the output nuclei become impaired. This imbalance leads to an increased inhibitory GABA-ergic output to the thalamus and to decreased glutamatergic thalamocortical feedback, which results in hypokinetic motor symptoms as well as hypoactivity in the cognitive functions, as it has been suggested previously (e.g., Owen, 2004). Specifically the impairment is attributed to those cognitive functions that involve the striatum-memory, visuospatial function, attention and working memory, executive decision, language, emotions. Previous pathological (Rinne et al., 1989; Paulus and Jellinger, 1991) and positron emission tomography studies confirmed a correlation between caudate DA 
A

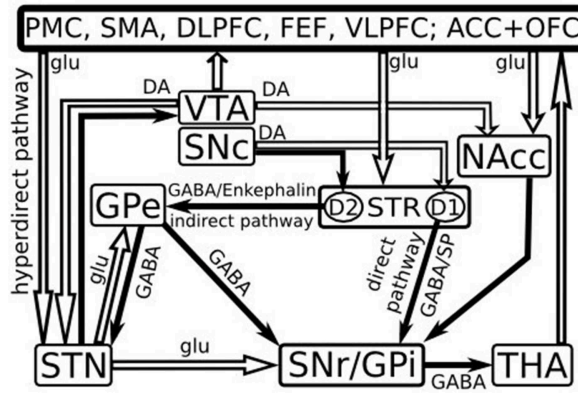

B

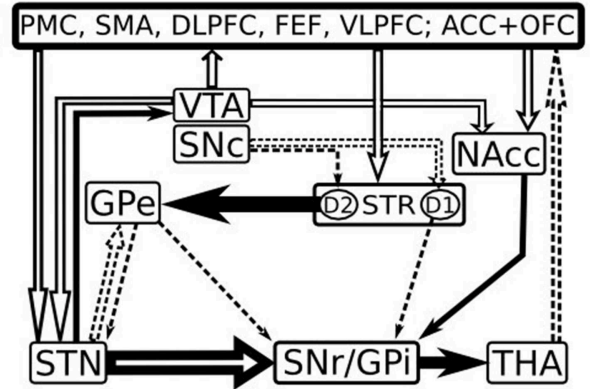

FIGURE 1 | Model of the basal ganglia connectivity in healthy (A) and in early Parkinson's disease (B) [Adapted after Kalivas and Nakamura (1999), Dudel et al. (2002), Nambu et al. (2002), Gubellini et al. (2009) and Cools (2006)]. Open and filled arrows represent excitatory glutamatergic (glu) and inhibitory gabaergic (GABA) projections. PMC, Premotor cortex; SMA, supplementary motor area; DLPFC, dorsolateral prefrontal cortex; FEF, frontal eye fields; VLPFC, ventrolateral prefrontal cortex; ACC, anterior cingulate cortex; OFC, orbitofrontal cortex; VTA, ventral tegmental area; SNc, substantia nigra pars compacta; SNr, substantia nigra pars reticulata; NAcc, nucleus accumbens; GPe, external segment of the globus pallidus; GPi, internal segment of the globus pallidus; STR, striatum; STN, subthalamic nucleus; THA, thalamus; DA, dopamine; SP, Substance P; D1, D1 class DA receptors; D2, D2 class DA receptors.

loss and neuropsychological performance in PD patients (Marié et al., 1999; Brück et al., 2001) suggesting a preferential role for this system in cognitive impairment (Ito et al., 2002).

In patients with $\mathrm{PD}$, cognitive impairment is frequently observed, especially with respect to executive functions (Cools, 2006), which are cognitive mechanisms through which performance is optimized in situations requiring the simultaneous operation of different processes (Morris et al., 1990). Executive control is especially active when the action or response is novel or complex (Norman and Shallice, 1986) such as pursuing a long-term goal requiring the completion of multiple intermediate sub-goals and behavior. Executive functioning refers to (1) switching attention between different processes (attentional set-shifting); (2) directing attention to a relevant stimulus and inhibiting the irrelevant stimuli (goal-directed action); (3) coding and checking the contents of memory storage (working memory) and (4) concept formation and planning strategies (Cools, 2006).

\section{Striatal Impairment in Attentional Set-shifting}

Attentional set-shifting is probably the most widely studied executive deficit in PD (Cools et al., 1984; Downes et al., 1989; Owen et al., 1992; Van Spaendonck et al., 1996; Monchi et al., 2004) but it is also impaired in patients with prefrontal cortex (PFC) lesions (Gotham et al., 1988; Cools et al., 2001b). The Wisconsin Card Sorting Task (WCST) is the most commonly used test to assess set-shifting in humans (Milner, 1963; Nelson, 1976) and involves matching test cards to one of four reference cards according to three possible classification rules. Participants must use feedback in order to select the correct rule, as it is not explicitly given. After a fixed number of correct matches, the rule is changed without notice and participants must switch to a new rule for classification, constituting a set-shift. Using an event-related fMRI protocol in healthy controls, we showed the implication of two cortico-striatal loops during different WCST stages. When planning a setshift, the ventrolateral PFC (VLPFC), the caudate nucleus, and the thalamus were significantly activated, while the execution of the set-shift solicited the posterior PFC and the putamen (Monchi et al., 2001). The same protocol was subsequently used in early-stage PD patients (following overnight DA-ergic medication removal) and matched controls (Monchi et al., 2004). The results reduced activation in the PD group in the VLPFC when receiving negative feedback and the posterior prefrontal cortex when matching following negative feedback. Activity in these areas specifically correlated with the striatum in controls. By contrast, greater activation was found in the PD group in areas that were not co-activated with the striatum in controls. These results suggest that both nigrostriatal dopamine depletion and intra-cortical dopamine deficiency may play a role in cognitive deficits in $\mathrm{PD}$, depending on the involvement of the striatum in the task at hand (see below). Furthermore, using the same protocol in early PD patients divided into two groups based on the presence of $\mathrm{MCI}, \mathrm{PD}$ patients without mild cognitive impairment (PD-non-MCI) "off" medication, revealed patterns of activation similar to healthy individuals from our previous studies when planning a set-shift (Monchi et al., 2004, 2007; Jubault et al., 2009) with significant activation in the VLPFC and caudate nucleus. In contrast, PD patients who had mild cognitive impairment (PD-MCI) had no significant activation in these regions (Nagano-Saito et al., 2014). Also, when matching following the set-shift, the PD-non-MCI group revealed significant activity in the premotor cortex but not the putamen resembling previous $\mathrm{PD}$ "ON" medication results (Jubault et al., 2009). Similar results have been observed in PD$\mathrm{MCI}$ and PD-non-MCI patients while performing a working memory task (Ekman et al., 2012; Monchi and Stoessl, 2012). The finding of striatal activation in the WCST is consistent with the possibility that the basal ganglia are involved in selecting the relevant action among competing motor responses (Mink and Thach, 1993). 


\section{Striatal Impairment in Goal-directed Action and Planning Strategies}

The Tower of London (Shallice, 1982) has often been used to analyze the failure of goal-directed action and planning strategies in PD. During this test patients are required to move a set of three colored balls around in "pockets" or "socks" to match a goal arrangement presented at the top of the screen (Owen et al., 1990). This task involves several stages (1) evaluation of the overall situation-understanding the differences between the initial state and the goal; (2) defining the sequence of moves that are necessary to achieve the goal; and (3) executing the correct solution. This task has been shown to recruit the caudate nucleus and the dorsolateral prefrontal cortex (Owen et al., 1996). In healthy controls, when the difficulty of the problem was increased, there was an increase in caudate nucleus activity (Owen et al., 1996; Dagher et al., 1999), while increasing the number of moves resulted in increased activity in the putamen (Dagher et al., 1999). PD patients at the early stage of the disease spent more time on planning the strategy than the controls (Owen et al., 1992). Furthermore, according to a functional neuroimaging study, the right caudate nucleus activity has been reported to be impaired in patients with mild PD compared with healthy controls when performing the task (Dagher et al., 2001). Interestingly, an eye-gaze behavior study has shown that PD patients seemed to fail to attend appropriately to the goals of the task (Hodgson et al., 2002).

It is clear that striatum impairment in PD leads to impaired goal-directed action and planning strategies. However, there may be two different reasons for this: (1) the inability to identify and maintain relevant goal information, or (2) bradyphrenia, i.e., slower thinking and an increase in the time taken to solve problems while the process of problem solving is preserved. Additionally, problem solving is likely not uniquely a striatal function but also a frontal one. Previous studies reported that impaired problem solving was present in patients with frontal lobe lesions (Owen et al., 1990). Indeed, it has been reported that abnormal striatal activation in $\mathrm{PD}$ was accompanied by a performance deficit similar to the one observed in patients with frontal lobe damage (Owen et al., 1993), but there were no abnormalities in the regional cerebral blood flow in the prefrontal cortex (Dagher et al., 2001). Additionally, patients with frontal lobe damage did not reveal longer thinking times during Tower of London task but they required more moves to reach the goal (Owen et al., 1990). This would suggest that striatum is responsible for the goal-directed deficit. Furthermore, according to some reports, medicated PD patients were shown to be impaired in the amount of time spent thinking about the solution (planning) (Owen et al., 1992), while another Tower of London study reported that even if PD patients directed their eyes toward the workspace, during planning like healthy controls, they divided their attention equally between the goals and the workspace. This suggests that the planning deficit in PD is due to abnormal encoding and maintenance of current goals (Hodgson et al., 2002). In conclusion to this section, it seems that the striatum is responsible for efficient goal-directed actions (encoding and maintaining the goals), but that the striatal dysfunction and the increased inhibitory GABA-ergic output to the thalamus that is present in PD, lead to both to an increased amount of time spent thinking and planning as well as with respect to goal-directed actions.

\section{Striatal Impairment in Working Memory and Decision-making}

Dopamine (DA) innervation to the prefrontal cortex and the striatum is critical for normal decision-making and working memory function both at the cellular and behavioral levels (Goldman-Rakic, 1995; Williams and Goldman-Rakic, 1995). Working memory is important for the ability to hold and manipulate information when involved in problem solving and decision making (Frank et al., 2007). Specifically, D1-receptor activation in the striatum (the direct pathway) has been shown to stabilize neuronal ensembles with high activity in the PFC, and this was suggested to be a method of maintaining the information within working memory (Durstewitz and Seamans, 2006). On the other hand, D2-receptors (the indirect pathway) appears to destabilize neuronal ensembles and makes them more susceptible to neuronal input, a state that has been considered as updating the information in working memory (Durstewitz et al., 2000). Working memory performance is also compromised in both PD patients and those with frontal lobe lesions, even if the reasons of impairment are different. One study showed that both groups of patients are impaired on a test that requires the selection and sequencing between a series of sub-goals (Owen et al., 1990, 1992). Participants were required to search for hidden "tokens" through boxes and to avoid the boxes that previously were associated with reward (between search) and to avoid returning to boxes that were previously opened and shown to be empty (within search) (Owen et al., 1990). Both groups of patients-PD and frontal lobe-lesioned-showed "between search" errors when compared with healthy controls (Owen et al., 1992), but PD patients did not have significant "within search errors," unlike frontal lobe-lesioned ones (Owen et al., 1996). Other studies also confirmed that working memory dysfunctions was associated with reduced activity (Lewis et al., 2003) and abnormal blood flow (Owen et al., 1998) in the caudate nucleus in PD patients who were executively impaired. Additionally, structural studies revealed that larger caudate size in the individuals deemed at ultra-high risk of psychosis was associated with greater errors on a spatial working memory task (Hannan et al., 2010). These results underline that frontal lobe is associated with performing the search and adopting strategies and organization with working memory (because the frontal lobe is likely less impaired in early PD) while the caudate nucleus becomes involved when there is a necessity of self-generated novel actions that would alternate effectively between important sub-goals and consequently modifies the behavior.

\section{Striatal Impairment in Procedural Learning}

Learning associations between stimuli and responses or categories is an important ability across species (Wise and 
Murray, 2000), and the striatum, particularly the caudate nucleus, plays a key role in such learning (Seger and Cincotta, 2005). The cortico-striatal circuitry has been emphasized to have a critical role in learning, and specifically in supporting the "procedural" learning system (Eichenbaum and Cohen, 2001; Shohamy et al., 2004). In fact, studies revealed that PD patients were slower during learning of an associative task, but they were unimpaired in the process of transferring the information, while patients with hippocampal atrophy showed the opposite pattern-good initial learning and impaired ability to transfer when familiar stimuli were presented in novel recombination (Swainson et al., 2000; Myers et al., 2003). Further investigations using a behavioral task in which participants viewed arbitrary visual patterns and used them to predict one of two possible outcomes, revealed that caudate nucleus contributes to learning in two distinct ways. Activity associated with successful classification learning (correct categorization) is concentrated to the body and tail of the caudate nucleus, while activity associated with feedback processing (the result of incorrect categorization) is concentrated to the head of the caudate nucleus (Seger and Cincotta, 2005). Patients with early $\mathrm{PD}$ were shown to be much more impaired at rule-based category learning than at information classification learning (Ashby et al., 2003). This is in line with the progressive neurodegeneration pattern in PD (Kish et al., 1988) with an increased rate in the head of the caudate nucleus-hence worse functioning, and a lower extent of neurodegeneration in the caudate nucleus tail.

\section{Interrelation between Striatum and Prefrontal Cortex}

Executive functions are widely associated with the frontal lobe, in particular with the dorsolateral prefrontal cortex (DLPFC), which is involved in certain aspects of working memory (Petrides, 2000) and cognitive flexibility (Milner, 1963; GoldmanRakic, 1987). Specifically, anatomical studies showed that the most rostrodorsal extent of the caudate head is connected with the DLPFC (Yeterian and Pandya, 1991) while PET studies demonstrated increased PFC activation in PD patients performing tests of executive function (Owen et al., 1998; Dagher et al., 2001). From this point of view, in PD patients one would expect diminished activity in the DLPFC as well, considering that within the caudate nucleus DA depletion is greatest in the caudate head (to a maximum of about $90 \%$ ). Nevertheless, our previous studies showed that increase and decrease in PFC activity in patients with $\mathrm{PD}$ is related to whether the striatum is necessary for the task or not (Monchi et al., 2004, 2007, 2010). Specifically, we revealed a decrease in PFC activity (hypoactivation) of patients with $\mathrm{PD}$ off medication compared with healthy controls, for tasks that recruit the striatum in healthy controls (i.e., planning a set-shift). In contrast, when performing tasks that do not require the striatum (i.e., task execution without changing the rule) in healthy controls, patients with PD showed significant prefrontal and parietal increases in activity-hyperactivationusually unrelated to the task (Monchi et al., 2007). Previous investigations in PD patients "on" medication compared to those in the "off" state suggested that DA level accounted for the greater PFC activation in PD “on" medication (Cools et al., 2002; Mattay et al., 2002). These hyperactivations can be explained by an increase of DA support through the mesocortical projections, by which neurons from the ventral tegmental area (VTA) and the medial SNc project to the frontal lobe (Tzschentke, 2001; Grahn et al., 2009). Unlike the nigrostriatal DA-ergic system, which refers to the SNc DA [and which has been termed also as mesostriatal, because it refers to the SNc-VTA complex (Lindvall et al., 1977)], the VTA DA-ergic neurons project to the PFC (mesocortical pathway) and to the ventral striatum (mesolimbic pathway) (Björklund and Dunnett, 2007). In fact, it has been shown that cortical DA has a critical role in executive functions and high-level cognition (Murphy et al., 1996; Watanabe et al., 1997). Since DA neurons in the substantia nigra degenerate much earlier in the disease than neurons in the VTA (Agid et al., 1987a,b; Kish et al., 1988), activity during cognitive tasks of the cortical regions could be modulated by DA replacement through the mesocortical pathway (Tzschentke, 2001; Grahn et al., 2009).

On the other hand, our studies revealed that levodopa showed no effect on the activity of the cognitive frontostriatal loop which included the DLPFC and the caudate nucleus, despite a significant effect on the activity of motor regions (Jubault et al., 2009; Martinu et al., 2012). A possible explanation for this increased activity in the DLPFC might be that mesocortical projections innervate predominantly the medial PFC, the infralimbic and prelimbic subareas (Tzschentke, 2001), hence PFC reveals a compensatory pattern not associated with DA concentration. This would suggest that even if in healthy controls the frontal cortex might not normally get involved in certain cognitive functions of the striatum, it becomes engaged in order to maintain a specific activity, as suggested previously (Samuel et al., 1997). Another explanation is that mesocortical projections have a diminished responsiveness to DA agonists and antagonists (Bannon and Roth, 1983), hence the absence of any effect on the activity of the cognitive fronto-striatal loop in our study. Nevertheless, a recent fMRI study in de-novo (untreated) PD patients during a set-shifting task, indicated that some of these frontal and parietal hyper-activation may be compensatory (Gerrits et al., 2015). It is likely that these hyperactivity patterns can represent both a mesocortical imbalance and compensation, depending on various factors, including the exact nature of the task, the advancement of the disease and the amount and type of dopamine medication being taken.

\section{Ventral Striatum Impairment and Cognitive Changes}

Ventral striatum includes nucleus accumbens, rostral/ventral caudate nucleus and putamen. These regions are connected with orbital, medial (Haber et al., 1995) and ventral PFC (Yeterian and Pandya, 1991) forming the limbic loop, and are involved in emotional processing, motivational and stereotyped behavior, attention deficit disorder, hyperactivity disorder, compulsive disorders, Tourette's syndrome (Grabli et al., 2004), and reversal of stimulus reward associations (Nauta, 1971; Rolls, 2000). Furthermore, the nucleus accumbens is essential in integrating cortical and limbic information into goal-directed behavior 
(Pennartz et al., 1994). Several studies reported that in the earlier stages of PD development, DA depletion is restricted to the putamen and the dorsal caudate nucleus, while in the later stages DA depletion progresses to the more ventral parts of the striatum and the mesocortico-limbic DA-ergic system (Rosvold, 1972; Kish et al., 1988; Swainson et al., 2000; Cools et al., 2001a). This uneven pattern of striatal DA loss has been confirmed by postmortem neurochemical analysis in patients with PD (Kish et al., 1988). The different spatiotemporal progression of DA depletion within the striatum and the terminal distribution of its cortical afferents may be the best explanation for the evolving pattern of cognitive impairments observed in $\mathrm{PD}$ patients (Gotham et al., 1988). Specifically, we previously showed that PD patients who had MCI presented a higher rate of volume diminishment over time in the nucleus accumbens and a higher rate of cortical thinning in comparison to PD patients without MCI and to healthy controls (Hanganu et al., 2014).

On the other hand, the different level of DA depletion leaves room for DA overdosage due to DA-ergic treatment. The "over-dose" hypothesis has been discussed by many studies previously (Gotham et al., 1988; Swainson et al., 2000; Cools et al., 2001a) and it states that levodopa doses necessary to remedy the DA lack in severely depleted brain areas, such as the putamen, would detrimentally "over-dose" relatively intact brain areas in early PD, such as the ventral striatum and its connections to the orbital PFC. In fact, previous studies reported the impairment of ventral striatum in early disease with respect to DA therapy. Learning was most commonly impaired in PD patients tested on DA replacement therapy. Cognitive tasks such as probabilistic reversal learning, that challenges the ventral frontostriatal circuit (ventral PFC and ventral striatum), revealed decreased performance in $\mathrm{PD}$ patients with DA-ergic treatment, although PD patients off medication showed similar performance to controls (Cools et al., 2001a; Torta et al., 2009; Jahanshahi et al., 2010). Other studies in PD reported impaired learning of discrimination tasks (Shohamy et al., 2006) and sequences associated with DA-ergic medication usage (Feigin et al., 2003; Seo et al., 2010; Tremblay et al., 2010). DA treatment in PD patients also yielded reduced facilitation for consecutive, consistent stimulus-stimulus pairings in a selection task compared to normal implicit learning (MacDonald et al., 2011). Furthermore, once a stimulus-reward association was learned, reversing probabilities of stimulus-reward associations was also impaired in PD patients on medication (Swainson et al., 2000; Cools et al., 2001a, 2006; Graef et al., 2010; MacDonald et al., 2011). Time estimation was also affected. Increased response time was reported in a simple reaction task in PD patients after administration of DA in comparison to PD patients off medication and healthy controls (Müller et al., 2001).

The nucleus accumbens is also thought to be involved in inhibitory control processes (Christakou et al., 2004) and increased impulsive choice (Cardinal et al., 2001). In the case of PD patients, impulsive betting was noted after DA treatment, despite appropriate and deliberate decision making (Cools et al., 2003; Torta et al., 2009). Other studies also reported an increased number of impulse control disorders in PD patients on medication, such as pathological gambling, compulsive sexual behavior, compulsive buying, and binge eating (Ray and Strafella, 2010; Weintraub et al., 2010).

In line with the "overdose" hypothesis, studies reported an improvement of functions associated with ventral striatum during "off" state. Specifically, improvements were shown in the learning to avoid choices that lead to negative outcomes in comparison to learning from positive outcomes (Frank et al., 2004). Other studies reported improvement in associative conditional learning (Gotham et al., 1988) and probabilistic reversal learning (Swainson et al., 2000; Cools et al., 2001a). These functions have been associated with the ventral striatum and the ventral PFC including the orbitofrontal cortex (Dias et al., 1996; Passingham et al., 2000; Cools et al., 2001a). On the other hand, levodopa withdrawal has been shown to impair PD patients in verbal fluency (Gotham et al., 1988), set-shifting tasks (Cools et al., 2001a), spatial recognition memory task (Swainson et al., 2000), and in tasks requiring trial and error (Frank et al., 2004), functions that are associated especially with the dorsal caudate and DLPFC (Owen et al., 1990).

The nucleus accumbens has also been heavily associated with reward processing (Schultz et al., 2000). Indeed various studies have investigated the effect of dopamine replacement therapy in PD in the context of stimulus-reward learning. It was reported that once a stimulus-reward association was learned, reversing probabilities of stimulus-reward associations was impaired in PD patients on dopaminergic medication (Swainson et al., 2000; Cools et al., 2001a, 2006; Graef et al., 2010; MacDonald et al., 2011). A two-fold study by MacDonald et al. (2011) used a simple selection task to elucidate functions mediated by the ventral and dorsal striatum respectively with fMRI in healthy individuals, and to better understand the cognitive effects of dopamine replacement in PD testing them behaviourally with the task once ON their usual dose of DA-ergic medication and once following overnight withdrawal. In healthy individuals, the congruent condition that involved consistent stimulus-stimulus associations across two consecutive events, without reward or feedback being provided, solicited significant ventral striatum activation, while the incongruent condition that involved conflicting relationships across two consecutive events (baring similarity to set-shifting) solicited significant activation in the head of the caudate nucleus. In PD patients DA replacement impaired encoding and facilitation of consistent stimulusstimulus relations across trials in the congruent condition relying on ventral striatum, while it enhanced interference related to assimilating conflicting influences on selection across trials in the incongruent condition relying on dorsal striatum. These studies gave support that impairments specific to the ventral striatum in PD patients can be explained by the "over-dose" hypothesis (Gotham et al., 1988; Swainson et al., 2000; Cools et al., 2001a).

\section{Striatum and Cerebellum Relationship in PD with Respect to Cognitive Changes}

It has been suggested that cerebellum may compensate for impaired basal ganglia cognitive function (Strick et al., 
2009; Appel-Cresswell et al., 2010) and several fMRI studies reported evidence that cerebello-thalamo-cortical loop increases its activity to compensate for degeneration in the striatothalamo-cortical loop to maintain a near-normal motor function (Glickstein and Stein, 1991). This compensational patterns are further explained by the presence of two main cerebellum circuits-the "motor" loop, projecting from the motor and premotor cortex to the dentate nucleus, and the "prefrontal" loop, that connects the posterior PFC (Brodmann Area 9/46) and the dentate nucleus (Kelly and Strick, 2003). The prefrontal loop has been associated with cognitive functions (Strick et al., 2009). Furthermore, recent evidence reported direct connections between striatum and cerebellar circuits (Bostan and Strick, 2010) - a tri-synaptic connection between the GPe and the dentate nucleus (Hoshi et al., 2005) and a bi-synaptic projection from the STN to the cerebellar cortex via pontine nuclei (Bostan et al., 2010). Altogether, this gives strong support that cerebellum is an organized compartment used for the integration of non-motor functions such as emotion, working memory, and language, as suggested previously (Stoodley and Schmahmann, 2009).

In $\mathrm{PD}$ patients, it has been argued that cerebellum has a compensatory role because when patients were off medication they revealed increased activation in the cerebellum during externally guided motor tasks, compared with healthy controls and with PD patients on medication (Rascol et al., 1997; Cerasa et al., 2006; Yu et al., 2007), as well as during internally generated movements (Cerasa et al., 2006; Yu et al., 2007). Furthermore, a negative correlation has been reported between cerebellum and contralateral putamen in PD patients off medication, suggesting that cerebellum activity increases in order to compensate the reduced putamen activation (Yu et al., 2007). Furthermore, PD patients off medication, when compared to healthy controls, revealed decreased functional connectivity in the supplementary motor area, DLPFC and putamen, while cerebellum, primary motor cortex, and parietal cortex showed increased connectivity ( $\mathrm{Ng}$ et al., 2010). Levodopa administration relatively normalized this connectivity pattern in PD patients.

It is also worth to note that one of cerebellum functions regarding cognition, is its timing capacity. Patients with cerebellar damage have difficulties accurately producing and perceiving time intervals (Ivry and Keele, 1989) and due to this, internal cognitive states may no longer be appropriately selected and sequenced at a fine level, which may exhibit problems with task-shifting and other forms of executive control (Strick et al., 2009). Our previous work with set-shifting tasks reported a decrease in timing activity in the prefrontal regions of patients with PD off medication compared to healthy controls for tasks that require the striatum in healthy controls (Monchi et al., 2007).

On the other hand, several researchers presented contrasting results. Hosokai and colleagues didn't find any significant increase in cerebellar metabolism both in PD-demented and PD-MCI patients in comparison to $\mathrm{PD}$ patients without MCI (Hosokai et al., 2009). Furthermore, one previous PET study reported a negative correlation between the cerebellum metabolism and regional cerebral blood flow both in PD patients and in healthy controls during procedural memory processes (Dagher et al., 2001). These results indicate that the cerebellum does not necessarily compensate for cognitive impairment of basal ganglia origin. Habas et al. (2009) also questioned cerebellum's cognitive functions due to failure of some studies to find significant cognitive impairment in cerebellar lesion patients (Helmuth et al., 1997; Thier et al., 1999; Haarmeier and Thier, 2007). Furthermore, in their reports Glickstein (2006) and Glickstein et al. (2011) failed to replicate previous studies reporting cerebellar contribution to cognition in PD even when using a low threshold. Finally, it has also been argued that the cerebellum activation in cognition can be subject to contamination by skeletal or eye movements (Strick et al., 2009).

In summary, the hypothesis that cerebellar circuits may compensate for impaired basal ganglia cognitive function in PD, as suggested previously (Stoodley and Schmahmann, 2009; Appel-Cresswell et al., 2010), still remains unresolved and further investigations are necessary.

\section{Conclusion}

Striatum impairment in PD is caused initially by a diminished modulatory effect of DA from the $\mathrm{SNc}$ which results in enhanced GPi activation, increased inhibitory output to the thalamus and decreased thalamocortical feedback. Such a dysregulation destabilizes neuronal input, affecting the frontostriatal loops, and impairing cognitive function. DA replacement therapy increases the striatum modulatory function, yet it also induces an overdose effect on the structures that have a relatively normal DA level, impairing their functions (e.g., ventral striatum) and as the disease continues to progress, cognitive impairment progresses along. In the initial stages of PD development PFC maintains a normal cognitive activity, either due to mesocortical DA sources or due to compensational patterns, which makes the cognitive impairment profile to be restricted to the dorsal striatum dysfunction. Nevertheless, the present DA replacement therapies cannot avoid further cognitive decline, since it has been shown that up to $75 \%$ of PD patients eventually develop dementia (Aarsland and Kurz, 2010). Furthermore, some studies reported that intellectual deterioration does not seem to result from dysfunction of DAergic mechanisms (Pillon et al., 1989). Taken together, these data suggest that cognitive disturbances in $\mathrm{PD}$ are related both to nigrostriatal, mesolimbic, and mesocortical DA-ergic systems as well as non-striatal and non-dopaminergic origins. Specifically, abnormalities in other systems have been found in PD (Agid et al., 1987a) - the cholinergic septo-hippocampal and innomasto-cortical pathways, the noradrenergic coeruleocortical neurons and the serotoninergic neurons (dorsal raphe nuclei) (Ruberg and Agid, 1988; Jellinger, 1999). Relationships between lesions of cholinergic (Sadeh et al., 1982; Bohnen et al., 2006; Ziabreva et al., 2006) and noradrenergic (Cash et al., 1987; Delaville et al., 2011; McMillan et al., 2011) systems and cognitive 
impairment in $\mathrm{PD}$ patients have been reported previously. Furthermore, degeneration of cortical neurons or decreases in cortical peptide concentrations (Agid et al., 1987b) may also contribute to cognitive impairment in PD. These systems should also be addressed in order to encircle the whole extent of striatal and non-striatal cognitive dysfunction in PD.

\section{References}

Aarsland, D., and Kurz, M. W. (2010). The epidemiology of dementia associated with Parkinson disease. J. Neurol. Sci. 289, 18-22. doi: 10.1016/j.jns.2009. 08.034

Agid, Y., Javoy-Agid, F., and Ruberg, M. (1987a). "Biochemistry of neurotransmitters in Parkinson's disease," in Movement Disorders Vol. 2, eds C. D. Marsden and S. Fahn (London: Butterworth), 166-230.

Agid, Y., Ruberg, M., Dubois, B., and Pillon, B. (1987b). "Anatomoclinical and biochemical concepts of subcortical dementia," in Cognitive Neurochemistry, eds S. M. Stahl, S. D. Iversen, and E. C. Goodman (Oxford: Oxford University Press), 248-271.

Albin, R. L., Young, A. B., and Penney, J. B. (1989). The functional anatomy of basal ganglia disorders. Trends Neurosci. 12, 366-375. doi: 10.1016/01662236(89)90074-X

Alexander, G. E., and Crutcher, M. D. (1990). Functional architecture of basal ganglia circuits: neural substrates of parallel processing. Trends Neurosci. 13, 266-271. doi: 10.1016/0166-2236(90)90107-L

Alexander, G. E., Crutcher, M. D., and Delong, M. R. (1989). Basal gangliathalamocortical circuits: parallel substrates for motor, oculomotor, "prefrontal" and "limbic" functions. Prog. Brain Res. 85, 119-146. doi: 10.1016/S00796123(08)62678-3

Alexander, G. E., Delong, M. R., and Strick, P. L. (1986). Parallel organization of functionally segregated circuits linking basal ganglia and cortex. Annu. Rev. Neurosci. 9, 357-381. doi: 10.1146/annurev.ne.09.030186.002041

Appel-Cresswell, S., de la Fuente-Fernandez, R., Galley, S., and Mckeown, M. J. (2010). Imaging of compensatory mechanisms in Parkinson's disease. Curr. Opin. Neurol. 23, 407-412. doi: 10.1097/WCO.0b013e32833b6019

Ashby, F. G., Noble, S., Filoteo, J. V., Waldron, E. M., and Ell, S. W. (2003). Category learning deficits in Parkinson's disease. Neuropsychology 17:115. doi: 10.1037/0894-4105.17.1.115

Bannon, M. J., and Roth, R. H. (1983). Pharmacology of mesocortical dopamine neurons. Pharmacol. Rev. 35, 53-68.

Björklund, A., and Dunnett, S. B. (2007). Dopamine neuron systems in the brain: an update. Trends Neurosci. 30, 194-202. doi: 10.1016/j.tins.2007.03.006

Bohnen, N. I., Kaufer, D. I., Hendrickson, R., Ivanco, L. S., Lopresti, B. J., Constantine, G. M., et al. (2006). Cognitive correlates of cortical cholinergic denervation in Parkinson's disease and parkinsonian dementia. J. Neurol. 253, 242-247. doi: 10.1007/s00415-005-0971-0

Bostan, A. C., Dum, R. P., and Strick, P. L. (2010). The basal ganglia communicate with the cerebellum. Proc. Natl. Acad. Sci. U.S.A. 107, 8452-8456. doi: $10.1073 /$ pnas. 1000496107

Bostan, A. C., and Strick, P. L. (2010). The cerebellum and basal ganglia are interconnected. Neuropsychol. Rev. 20, 261-270. doi: 10.1007/s11065-0109143-9

Brück, A., Portin, R., Lindell, A., Laihinen, A., Bergman, J., Haaparanta, M., et al. (2001). Positron emission tomography shows that impaired frontal lobe functioning in Parkinson's disease is related to dopaminergic hypofunction in the caudate nucleus. Neurosci. Lett. 311, 81-84. doi: 10.1016/S03043940(01)02124-3

Calabresi, P., Maj, R., Pisani, A., Mercuri, N. B., and Bernardi, G. (1992). Longterm synaptic depression in the striatum: physiological and pharmacological characterization. J. Neurosci. 12, 4224-4233.

Cardinal, R. N., Pennicott, D. R., Lakmali, C. L., Robbins, T. W., and Everitt, B. J. (2001). Impulsive choice induced in rats by lesions of the nucleus accumbens core. Science 292, 2499-2501. doi: 10.1126/science.1060818

\section{Acknowledgments}

This work was funded by an operating grant from the Canadian Institutes of Health Research (MOP-126017) and the Tourmaline Oil Chair in Parkinson's Disease to OM as well as a Parkinson Society Canada Basic Research Fellowship to AH.

Cash, R., Dennis, T., L'heureux, R., Raisman, R., Javoy-Agid, F., and Scatton, B. (1987). Parkinson's disease and dementia Norepinephrine and dopamine in locus ceruleus. Neurology 37, 42-42. doi: 10.1212/WNL.37.1.42

Cerasa, A., Hagberg, G. E., Peppe, A., Bianciardi, M., Gioia, M. C., Costa, A., et al. (2006). Functional changes in the activity of cerebellum and frontostriatal regions during externally and internally timed movement in Parkinson's disease. Brain Res. Bull. 71, 259-269. doi: 10.1016/j.brainresbull.2006.09.014

Christakou, A., Robbins, T. W., and Everitt, B. J. (2004). Prefrontal corticalventral striatal interactions involved in affective modulation of attentional performance: implications for corticostriatal circuit function. J. Neurosci. 24, 773-780. doi: 10.1523/JNEUROSCI.0949-03.2004

Cools, A. R., Van den Bercken, J. H., Horstink, M. W., Van Spaendonck, K. P., and Berger, H. J. (1984). Cognitive and motor shifting aptitude disorder in Parkinson's disease. J. Neurol. Neurosurg. Psych. 47, 443-453. doi: 10.1136/jnnp.47.5.443

Cools, R. (2006). Dopaminergic modulation of cognitive function-implications for l-DOPA treatment in Parkinson's disease. Neurosci. Biobehav. Rev. 30, 1-23. doi: 10.1016/j.neubiorev.2005.03.024

Cools, R., Barker, R. A., Sahakian, B. J., and Robbins, T. W. (2001a). Enhanced or impaired cognitive function in Parkinson's Disease as a function of dopaminergic medication and task demands. Cereb. Cortex 11, 1136-1143. doi: 10.1093/cercor/11.12.1136

Cools, R., Barker, R. A., Sahakian, B. J., and Robbins, T. W. (2001b). Mechanisms of cognitive set flexibility in Parkinson's disease. Brain 124, 2503-2512. doi: 10.1093/brain/124.12.2503

Cools, R., Barker, R. A., Sahakian, B. J., and Robbins, T. W. (2003). LDopa medication remediates cognitive inflexibility, but increases impulsivity in patients with Parkinson's disease. Neuropsychologia 41, 1431-1441. doi: 10.1016/S0028-3932(03)00117-9

Cools, R., Ivry, R. B., and D'esposito, M. (2006). The human striatum is necessary for responding to changes in stimulus relevance. J. Cogn. Neurosci. 18, 1973-1983. doi: 10.1162/jocn.2006.18.12.1973

Cools, R., Stefanova, E., Barker, R. A., Robbins, T. W., and Owen, A. M. (2002). Dopaminergic modulation of high-level cognition in Parkinson's disease: the role of the prefrontal cortex revealed by PET. Brain 125, 584-594. doi: 10.1093/brain/awf052

Dagher, A., Owen, A. M., Boecker, H., and Brooks, D. J. (1999). Mapping the network for planning: a correlational PET activation study with the Tower of London task. Brain 122, 1973-1987. doi: 10.1093/brain/122.10.1973

Dagher, A., Owen, A. M., Boecker, H., and Brooks, D. J. (2001). The role of the striatum and hippocampus in planning A PET activation study in Parkinson's disease. Brain 124, 1020-1032. doi: 10.1093/brain/124.5.1020

Delaville, C., Deurwaerdère, P. D., and Benazzouz, A. (2011). Noradrenaline and Parkinson's disease. Front. Syst. Neurosci. 5:31. doi: 10.3389/fnsys.2011.00031

Delong, M. R., and Wichmann, T. (2007). Circuits and circuit disorders of the basal ganglia. Arch. Neurol. 64, 20-24. doi: 10.1001/archneur.64.1.20

Dias, R., Robbins, T. W., and Roberts, A. C. (1996). Dissociation in prefrontal cortex of affective and attentional shifts. Nature 380, 69-72. doi: $10.1038 / 380069 \mathrm{a} 0$

Dorsey, E. R., Constantinescu, R., Thompson, J. P., Biglan, K. M., Holloway, R. G., Kieburtz, K., et al. (2007). Projected number of people with Parkinson disease in the most populous nations, 2005 through 2030. Neurology 68, 384-386. doi: 10.1212/01.wnl.0000247740.47667.03

Downes, J. J., Roberts, A. c., Sahakian, B. J., Evenden, J. L., Morris, R. G., and Robbins, T. W. (1989). Impaired extra-dimensional shift performance in medicated and unmedicated Parkinson's disease: evidence for a specific 
attentional dysfunction. Neuropsychologia 27, 1329-1343. doi: 10.1016/00283932(89)90128-0

Dubois, B., and Pillon, B. (1996). Cognitive deficits in Parkinson's disease. J. Neurol. 244, 2-8. doi: 10.1007/PL00007725

Dudel, J., Menzel, R., and Schmidt, R. (2002). Neurowissenschaft-Vom Molekül zur Kognition. Berlin; Heildelberg: Springer.

Durstewitz, D., and Seamans, J. (2006). Beyond bistability: biophysics and temporal dynamics of working memory. Neuroscience 139, 119-133. doi: 10.1016/j.neuroscience.2005.06.094

Durstewitz, D., Seamans, J. K., and Sejnowski, T. J. (2000). Neurocomputational models of working memory. Nat. Neurosci. 3, 1184-1191. doi: 10.1038/81460

Eichenbaum, H., and Cohen, N. J. (2001). From Conditioning to Conscious Recollection: Memory Systems of the Brain. New York, NY: Oxford University Press. doi: 10.1093/acprof:oso/9780195178043.001.0001

Ekman, U., Eriksson, J., Forsgren, L., Mo, S. J., Riklund, K., and Nyberg, L. (2012). Functional brain activity and presynaptic dopamine uptake in patients with Parkinson's disease and mild cognitive impairment: a cross-sectional study. Lancet Neurol. 11, 679-687. doi: 10.1016/S1474-4422(12)70138-2

Emre, M., Aarsland, D., Brown, R., Burn, D. J., Duyckaerts, C., Mizuno, Y., et al. (2007). Clinical diagnostic criteria for dementia associated with Parkinson's disease. Mov. Disord. 22, 1689-1707. doi: 10.1002/mds.21507

Feigin, A., Ghilardi, M. F., Carbon, M., Edwards, C., Fukuda, M., Dhawan, V., et al. (2003). Effects of levodopa on motor sequence learning in Parkinson's disease. Neurology 60, 1744-1749. doi: 10.1212/01.WNL.0000072263.03608.42

Frank, M. J., Samanta, J., Moustafa, A. A., and Sherman, S. J. (2007). Hold your horses: impulsivity, deep brain stimulation, and medication in parkinsonism. Science 318, 1309-1312. doi: 10.1126/science. 1146157

Frank, M. J., Seeberger, L. C., and O'Reilly, R. C. (2004). By carrot or by stick: cognitive reinforcement learning in parkinsonism. Science 306, 1940-1943. doi: $10.1126 /$ science. 1102941

Gerfen, C. R., Engber, T. M., Mahan, L. C., Susel, Z., Chase, T. N., Monsma, F., et al. (1990). D1 and D2 dopamine receptor-regulated gene expression of striatonigral and striatopallidal neurons. Science 250, 1429-1432. doi: $10.1126 /$ science. 2147780

Gerrits, N. J. H. M., van der Werf, Y. D., Verhoef, K. M. W., Veltman, D. J., Groenewegen, H. J., Berendse, H. W., et al. (2015). Compensatory fronto-parietal hyperactivation during set-shifting in unmedicated patients with Parkinson's disease. Neuropsychologia 68, 107-116. doi: 10.1016/j.neuropsychologia.2014.12.022

Giuffrida, R., Li Volsi, G., Maugeri, G., and Perciavalle, V. (1985). Influences of pyramidal tract on the subthalamic nucleus in the cat. Neurosci. Lett. 54, 231-235. doi: 10.1016/S0304-3940(85)80084-7

Glickstein, M. (2006). Thinking about the cerebellum. Brain 129, 288-290. doi: 10.1093/brain/awh728

Glickstein, M., and Stein, J. (1991). Paradoxical movement in Parkinson's disease. Trends Neurosci. 14, 480-482. doi: 10.1016/0166-2236(91)90055-Y

Glickstein, M., Sultan, F., and Voogd, J. (2011). Functional localization in the cerebellum. Cortex 47, 59-80. doi: 10.1016/j.cortex.2009.09.001

Goldman-Rakic, P. (1995). Cellular basis of working memory. Neuron 14, 477-485. doi: 10.1016/0896-6273(95)90304-6

Goldman-Rakic, P. S. (1987). Circuitry of the frontal association cortex and its relevance to dementia. Arch. Gerontol. Geriatr. 6, 299-309. doi: 10.1016/01674943(87)90029-X

Gotham, A. M., Brown, R. G., and Marsden, C. D. (1988). 'Frontal'cognitive function in patients with Parkinson's disease 'on'and 'off'levodopa. Brain 111, 299-321. doi: 10.1093/brain/111.2.299

Grabli, D., Mccairn, K., Hirsch, E. C., Agid, Y., Féger, J., François, C., et al. (2004). Behavioural disorders induced by external globus pallidus dysfunction in primates: I. Behavioural study. Brain 127, 2039-2054. doi: 10.1093/brain/awh220

Graef, S., Biele, G., Krugel, L. K., Marzinzik, F., Wahl, M., Wotka, J., et al. (2010). Differential influence of levodopa on reward-based learning in Parkinson's disease. Front. Hum. Neurosci. 4:169. doi: 10.3389/fnhum.2010.00169

Grahn, J. A., Parkinson, J. A., and Owen, A. M. (2009). The role of the basal ganglia in learning and memory: neuropsychological studies. Behav. Brain Res. 199, 53-60. doi: 10.1016/j.bbr.2008.11.020

Gubellini, P., Salin, P., Kerkerian-Le Goff, L., and Baunez, C. (2009). Deep brain stimulation in neurological diseases and experimental models: from molecule to complex behavior. Prog. Neurobiol. 89, 79-123. doi: 10.1016/j.pneurobio.2009.06.003

Haarmeier, T., and Thier, P. (2007). The attentive cerebellum - myth or reality? Cerebellum 6, 177-183. doi: 10.1080/14734220701286187

Habas, C., Kamdar, N., Nguyen, D., Prater, K., Beckmann, C. F., Menon, V., et al. (2009). Distinct cerebellar contributions to intrinsic connectivity networks. J. Neurosci. 29, 8586-8594. doi: 10.1523/JNEUROSCI.1868-09.2009

Haber, S. N., Kunishio, K., Mizobuchi, M., and Lynd-Balta, E. (1995). The orbital and medial prefrontal circuit through the primate basal ganglia. J. Neurosci. 15, 4851-4867.

Haber, S. N., and Nauta, W. G. (1983). Ramifications of the globus pallidus in the rat as indicated by patterns of immunohistochemistry. Neuroscience $9,245-260$. doi: 10.1016/0306-4522(83)90291-9

Hanganu, A., Bedetti, C., Degroot, C., Mejia-Constain, B., Lafontaine, A.-L., Soland, V., et al. (2014). Mild cognitive impairment is linked with faster rate of cortical thinning in patients with Parkinson's disease longitudinally. Brain 137, 1120-1129. doi: 10.1093/brain/awu036

Hannan, K. L., Wood, S. J., Yung, A. R., Velakoulis, D., Phillips, L. J. Soulsby, B., et al. (2010). Caudate nucleus volume in individuals at ultrahigh risk of psychosis: a cross-sectional magnetic resonance imaging study. Psychiatry Res. Neuroimag. 182, 223-230. doi: 10.1016/j.pscychresns.2010. 02.006

Helmuth, L. L., Ivry, R. B., and Shimizu, N. (1997). Preserved performance by cerebellar patients on tests of word generation, discrimination learning, and attention. Learn. Mem. 3, 456-474. doi: 10.1101/lm.3.6.456

Hirtz, D., Thurman, D. J., Gwinn-Hardy, K., Mohamed, M., Chaudhuri, A. R., and Zalutsky, R. (2007). How common are the "common" neurologic disorders? Neurology 68, 326-337. doi: 10.1212/01.wnl.0000252807.38124.a3

Hodgson, T. L., Tiesman, B., Owen, A. M., and Kennard, C. (2002). Abnormal gaze strategies during problem solving in Parkinson's disease. Neuropsychologia 40, 411-422. doi: 10.1016/S0028-3932(01)00099-9

Hoshi, E., Tremblay, L., Féger, J., Carras, P. L., and Strick, P. L. (2005). The cerebellum communicates with the basal ganglia. Nat. Neurosci. 8, 1491-1493. doi: $10.1038 / \mathrm{nn} 1544$

Hosokai, Y., Nishio, Y., Hirayama, K., Takeda, A., Ishioka, T., Sawada, Y., et al. (2009). Distinct patterns of regional cerebral glucose metabolism in Parkinson's disease with and without mild cognitive impairment. Mov. Disord. 24, 854-862. doi: $10.1002 / \mathrm{mds} .22444$

Ito, K., Nagano-Saito, A., Kato, T., Arahata, Y., Nakamura, A., Kawasumi, Y., et al. (2002). Striatal and extrastriatal dysfunction in Parkinson's disease with dementia: a 6-[18F]fluoro-l-dopa PET study. Brain 125, 1358-1365. doi: 10.1093/brain/awf134

Ivry, R. B., and Keele, S. W. (1989). Timing functions of the cerebellum. J. Cogn. Neurosci. 1, 136-152. doi: 10.1162/jocn.1989.1.2.136

Jahanshahi, M., Wilkinson, L., Gahir, H., Dharminda, A., and Lagnado, D. A. (2010). Medication impairs probabilistic classification learning in Parkinson's disease. Neuropsychologia 48, 1096-1103. doi: 10.1016/j.neuropsychologia.2009.12.010

Jellinger, K. A. (1999). "Neuropathological correlates of mental dysfunction in Parkinson's disease: an update," in Mental Dysfunction in Parkinson's Disease: II, eds E. C. Wolters, P. Scheltens, and H. W. Berendse (Utrecht: Academic Pharmaceutical Productions), 82-105.

Jubault, T., Monetta, L., Strafella, A. P., Lafontaine, A.-L., and Monchi, O. (2009). L-dopa medication in Parkinson's disease restores activity in the motor corticostriatal loop but does not modify the cognitive network. PLoS ONE 4:e6154. doi: 10.1371/journal.pone.0006154

Kalivas, P. W., and Nakamura, M. (1999). Neural systems for behavioral activation and reward. Curr. Opin. Neurobiol. 9, 223-227. doi: 10.1016/S09594388(99)80031-2

Kehagia, A. A., Barker, R. A., and Robbins, T. W. (2010). Neuropsychological and clinical heterogeneity of cognitive impairment and dementia in patients with Parkinson's disease. Lancet Neurol. 9, 1200-1213. doi: 10.1016/S1474$4422(10) 70212-\mathrm{X}$

Kelly, R. M., and Strick, P. L. (2003). Cerebellar loops with motor cortex and prefrontal cortex of a nonhuman primate. J. Neurosci. 23, 8432-8444.

Kish, S. J., Shannak, K., and Hornykiewicz, O. (1988). Uneven pattern of dopamine loss in the striatum of patients with idiopathic Parkinson's disease. N. Engl. J. Med. 318, 876-880. doi: 10.1056/NEJM198804073181402 
Lehéricy, S., Ducros, M., Van de Moortele, V., Francois, C., Thivard, L., Poupon, C., et al. (2004). Diffusion tensor fiber tracking shows distinct corticostriatal circuits in humans. Ann. Neurol. 55, 522-529. doi: 10.1002/ana.20030

Lewis, S. J. G., Dove, A., Robbins, T. W., Barker, R. A., and Owen, A. M. (2003). Cognitive impairments in early Parkinson's disease are accompanied by reductions in activity in frontostriatal neural circuitry. J. Neurosci. 23, 6351-6356.

Li, Y., Acerbo, M. J., and Robinson, T. E. (2004). The induction of behavioural sensitization is associated with cocaine-induced structural plasticity in the core (but not shell) of the nucleus accumbens. Eur. J. Neurosci. 20, 1647-1654. doi: 10.1111/j.1460-9568.2004.03612.x

Lindvall, O., Björklund, A., and Divac, I. (1977). Organization of mesencephalic dopamine neurons projecting to neocortex and septum. Adv. Biochem. Psychopharmacol. 16, 39-46.

Litvan, I., Goldman, J. G., Tröster, A. I., Schmand, B. A., Weintraub, D., Petersen, R. C., et al. (2012). Diagnostic criteria for mild cognitive impairment in Parkinson's disease: movement disorder society task force guidelines. Mov. Disord. 27, 349-356. doi: 10.1002/mds.24893

MacDonald, P. A., Macdonald, A. A., Seergobin, K. N., Tamjeedi, R., Ganjavi, H., Provost, J.-S., et al. (2011). The effect of dopamine therapy on ventral and dorsal striatum-mediated cognition in Parkinson's disease: support from functional MRI. Brain 134, 1447-1463. doi: 10.1093/brain/awr075

Marié, R. M., Barré, L., Dupuy, B., Viader, F., Defer, G., and Baron, J. C. (1999). Relationships between striatal dopamine denervation and frontal executive tests in Parkinson's disease. Neurosci. Lett. 260, 77-80. doi: 10.1016/S03043940(98)00928-8

Martinu, K., Degroot, C., Madjar, C., Strafella, A., and Monchi, O. (2012). Levodopa influences striatal activity but does not affect cortical hyper-activity in Parkinson's disease. Eur. J. Neurosci. 35, 572-583. doi: 10.1111/j.14609568.2011.07979.x

Mattay, V. S., Tessitore, A., Callicott, J. H., Bertolino, A., Goldberg, T. E., Chase, T. N., et al. (2002). Dopaminergic modulation of cortical function in patients with Parkinson's disease. Ann. Neurol. 51, 156-164. doi: 10.1002/ana.10078

McMillan, P. J., White, S. S., Franklin, A., Greenup, J. L., Leverenz, J. B., Raskind, M. A., et al. (2011). Differential response of the central noradrenergic nervous system to the loss of locus coeruleus neurons in Parkinson's disease and Alzheimer's disease. Brain Res. 1373, 240-252. doi: 10.1016/j.brainres.2010.12.015

Milner, B. (1963). Effects of different brain lesions on card sorting: the role of the frontal lobes. Arch. Neurol. 9, 90-100. doi: 10.1001/archneur.1963.00460070100010

Mink, J. W., and Thach, W. T. (1993). Basal ganglia intrinsic circuits and their role in behavior. Curr. Opin. Neurobiol. 3, 950-957. doi: 10.1016/09594388(93)90167-W

Monchi, O., Martinu, K., and Strafella, A. P. (2010). The Contribution of Neuroimaging for the Study of Cognitive Deficits in Parkinson's Disease. Clin. EEG Neurosci. 41, 76-81. doi: 10.1177/155005941004100206

Monchi, O., Petrides, M., Doyon, J., Postuma, R. B., Worsley, K., and Dagher, A. (2004). Neural bases of set-shifting deficits in Parkinson's disease. J. Neurosci. 24, 702-710. doi: 10.1523/JNEUROSCI.4860-03.2004

Monchi, O., Petrides, M., Mejia-Constain, B., and Strafella, A. P. (2007). Cortical activity in Parkinson's disease during executive processing depends on striatal involvement. Brain 130, 233-244. doi: 10.1093/brain/awl326

Monchi, O., Petrides, M., Petre, V., Worsley, K., and Dagher, A. (2001). Wisconsin Card Sorting revisited: distinct neural circuits participating in different stages of the task identified by event-related functional magnetic resonance imaging. J. Neurosci. 21, 7733-7741.

Monchi, O., and Stoessl, A. J. (2012). Imaging neural correlates of mild cognitive impairment in Parkinson's disease. Lancet Neurol. 11, 653-655. doi: 10.1016/S1474-4422(12)70162-X

Morris, R. G., Downes, J. J., and Robins, T. W. (1990). "The nature of the dysexecutive syndrome in Parkinson's disease," in Lines of Thinking: Reflections on the Psychology of Thought, Vol. 2, eds K. J. Gilhooly, M. T. G. Keane, R. H. Logie, and G. Erdos (Chichester: John Wiley and Sons), 247-258.

Müller, T., Benz, S., and Börnke, C. (2001). Delay of simple reaction time after levodopa intake. Clin. Neurophysiol. 112, 2133-2137. doi: 10.1016/S13882457(01)00653-8
Murphy, B. L., Arnsten, A. F., Goldman-Rakic, P. S., and Roth, R. H. (1996). Increased dopamine turnover in the prefrontal cortex impairs spatial working memory performance in rats and monkeys. Proc. Natl. Acad. Sci. U.S.A. 93, 1325-1329. doi: 10.1073/pnas.93.3.1325

Myers, C. E., Shohamy, D., Gluck, M. A., Grossman, S., Kluger, A., Ferris, S., et al. (2003). Dissociating hippocampal versus basal ganglia contributions to learning and transfer. J. Cogn. Neurosci. 15, 185-193. doi: 10.1162/089892903321208123

Nagano-Saito, A., Habak, C., Mejia-Constain, B., Degroot, C., Monetta, L., Jubault, T., et al. (2014). Effect of mild cognitive impairment on the patterns of neural activity in early Parkinson's disease. Brain. Neurobiol. Aging 35, 223-231. doi: 10.1016/j.neurobiolaging.2013.06.025

Nambu, A., Tokuno, H., and Takada, M. (2002). Functional significance of the cortico-subthalamo-pallidal 'hyperdirect'pathway. Neurosci. Res. 43, 111-117. doi: 10.1016/S0168-0102(02)00027-5

Nauta, W. J. (1971). The problem of the frontal lobe: a reinterpretation. J. Psychiatr. Res. 8, 167-187. doi: 10.1016/0022-3956(71)90017-3

Nelson, H. E. (1976). A modified card sorting test sensitive to frontal lobe defects. Cortex 12, 313-324. doi: 10.1016/S0010-9452(76)80035-4

Ng, B., Palmer, S., Abugharbieh, R., and Mckeown, M. J. (2010). Focusing effects of L-dopa in Parkinson's disease. Hum. Brain Mapp. 31, 88-97. doi: $10.1002 / \mathrm{hbm} .20847$

Norman, D. A., and Shallice, T. (1986). "Attention to action: willed and automatic control of behaviour," in Consciousness and Self-Regulation: Advances in Research and Theory, eds R. J. Davidson, G. E. Schwartz, and D. Shapiro (New York, NY: Springer), 1-18.

Owen, A. M., James, M., Leigh, P. N., Summers, B. A., Marsden, C. D., Quinn, N. P., et al. (1992). Fronto-striatal cognitive deficits at different stages of Parkinson's disease. Brain 115, 1727-1751. doi: 10.1093/brain/115.6.1727

Owen, A. M. (2004). Cognitive dysfunction in Parkinson's Disease: the role of frontostriatal circuitry. Neuroscientist 10, 525-537. doi: $10.1177 / 1073858404266776$

Owen, A. M., Downes, J. J., Sahakian, B. J., Polkey, C. E., and Robbins, T. W. (1990). Planning and spatial working memory following frontal lobe lesions in man. Neuropsychologia 28, 1021-1034. doi: 10.1016/0028-3932(90)90137-D

Owen, A. M., Doyon, J., Dagher, A., Sadikot, A., and Evans, A. C. (1998). Abnormal basal ganglia outflow in Parkinson's disease identified with PET. Implications for higher cortical functions. Brain 121(Pt 5), 949-965. doi: 10.1093/brain/121.5.949

Owen, A. M., Doyon, J., Petrides, M., and Evans, A. C. (1996). Planning and spatial working memory: a positron emission tomography study in humans. Eur. J. Neurosci. 8, 353-364. doi: 10.1111/j.1460-9568.1996.tb01219.x

Owen, A. M., Roberts, A. C., Hodges, J. R., and Robbins, T. W. (1993). Contrasting mechanisms of impaired attentional set-shifting in patients with frontal lobe damage or Parkinson's disease. Brain 116, 1159-1175. doi: 10.1093/brain/116.5.1159

Passingham, R. E., Toni, I., and Rushworth, M. F. S. (2000). "Specialisation within the prefrontal cortex: the ventral prefrontal cortex and associative learning," in Executive Controls and the Frontal Lobe: Current Issues, eds W. X. Schneider, A. M. Owen, and J. Duncan (Berlin; Heidelberg: Springer), 103-113.

Paulus, W., and Jellinger, K. (1991). The Neuropathologic basis of different clinical subgroups of Parkinson's disease. J. Neuropathol. Exp. Neurol. 50, 743-755. doi: 10.1097/00005072-199111000-00006

Pennartz, C. M., Groenewegen, H. J., and Lopes Da Silva, F. H. (1994). The nucleus accumbens as a complex of functionally distinct neuronal ensembles: an integration of behavioural, electrophysiological and anatomical data. Prog. Neurobiol. 42, 719-761. doi: 10.1016/0301-0082(94)90025-6

Petrides, M. (2000). "The role of the mid-dorsolateral prefrontal cortex in working memory," in Executive Control and the Frontal Lobe: Current Issues, eds W. X. Schneider, A. M. Owen, and J. Duncan (Berlin; Heidelberg: Springer), 44-54.

Pillon, B., Dubois, B., Cusimano, G., Bonnet, A.-M., Lhermitte, F., and Agid, Y. (1989). Does cognitive impairment in Parkinson's disease result from nondopaminergic lesions? J. Neurol. Neurosurg. Psych. 52, 201-206.

Rascol, O., Sabatini, U., Fabre, N., Brefel, C., Loubinoux, I., Celsis, P., et al. (1997). The ipsilateral cerebellar hemisphere is overactive during hand movements in akinetic parkinsonian patients. Brain 120, 103. doi: 10.1093/brain/120.1.103

Ray, N., and Strafella, A. P. (2010). Dopamine, reward, and frontostriatal circuitry in impulse control disorders in Parkinson's disease: insights from 
functional imaging. Clin. EEG Neurosci. 41, 87-93. doi: 10.1177/1550059410041 00208

Reynolds, J. N., Hyland, B. I., and Wickens, J. R. (2001). A cellular mechanism of reward-related learning. Nature 413, 67-70. doi: 10.1038/35092560

Rijk, M. C., Tzourio, C., Breteler, M. M., Dartigues, J. F., Amaducci, L., LopezPousa, S., et al. (1997). Prevalence of parkinsonism and Parkinson's disease in Europe: the EUROPARKINSON collaborative study. European community concerted action on the epidemiology of Parkinson's disease. J. Neurol. Neurosurg. Psych. 62, 10-15.

Rinne, J. O., Rummukainen, J., Paljärvi, L., and Rinne, U. K. (1989). Dementia in Parkinson's disease is related to neuronal loss in the medial substantia nigra. Ann. Neurol. 26, 47-50. doi: 10.1002/ana.410260107

Rolls, E. T. (2000). On the brain and emotion. Behav. Brain Sci. 23, 219-228. doi: $10.1017 / \mathrm{S} 0140525 \mathrm{X} 00512424$

Rosvold, H. E. (1972). The frontal lobe system: cortical-subcortical interrelationships. Acta Neurobiol. Exp. 32, 439-460.

Ruberg, M., and Agid, Y. (1988). "Dementia in Parkinson's disease," in Handbook of Psychopharmacology, eds L. L. Iversen, S. D. Iversen, and S. H. Snyder (New York, NY: Springer), 157-206.

Sadeh, M., Braham, J., and Modan, M. (1982). Effects of anticholinergic drugs on memory in Parkinson's disease. Arch. Neurol. 39, 666-667. doi: 10.1001/archneur.1982.00510220064017

Samii, A., Nutt, J. G., and Ransom, B. R. (2004). Parkinson's disease. Lancet 363, 1783-1793. doi: 10.1016/S0140-6736(04)16305-8

Samuel, M., Ceballos-Baumann, A. O., Blin, J., Uema, T., Boecker, H., Passingham, R. E., et al. (1997). Evidence for lateral premotor and parietal overactivity in Parkinson's disease during sequential and bimanual movements. A PET study. Brain 120, 963-976. doi: 10.1093/brain/120.6.963

Schultz, W., Tremblay, L., and Hollerman, J. R. (2000). Reward processing in primate orbitofrontal cortex and basal ganglia. Cereb. Cortex 10, 272-283. doi: $10.1093 /$ cercor/10.3.272

Seger, C. A., and Cincotta, C. M. (2005). The roles of the caudate nucleus in human classification learning. J. Neurosci. 25, 2941-2951. doi: 10.1523/JNEUROSCI.3401-04.2005

Seo, M., Beigi, M., Jahanshahi, M., and Averbeck, B. B. (2010). Effects of dopamine medication on sequence learning with stochastic feedback in Parkinson's disease. Front. Syst. Neurosci. 4:36. doi: 10.3389/fnsys.2010.00036

Shallice, T. (1982). Specific impairments of planning. Philos. Trans. R. Soc. Lond. B Biol. Sci. 298, 199-209. doi: 10.1098/rstb.1982.0082

Shohamy, D., Myers, C. E., Geghman, K. D., Sage, J., and Gluck, M. A. (2006). L-dopa impairs learning, but spares generalization, in Parkinson's disease. Neuropsychologia 44, 774-784. doi: 10.1016/j.neuropsychologia.2005.07.013

Shohamy, D., Myers, C. E., Grossman, S., Sage, J., Gluck, M. A., and Poldrack, R. A. (2004). Cortico-striatal contributions to feedback-based learning: converging data from neuroimaging and neuropsychology. Brain 127, 851-859. doi: 10.1093/brain/awh100

Steiner, H., and Gerfen, C. (1999). Enkephalin regulates acute D 2 dopamine receptor antagonist-induced immediate-early gene expression in striatal neurons. Neuroscience 88, 795-810. doi: 10.1016/S0306-4522(98)00241-3

Stoodley, C. J., and Schmahmann, J. D. (2009). Functional topography in the human cerebellum: a meta-analysis of neuroimaging studies. Neuroimage 44, 489-501. doi: 10.1016/j.neuroimage.2008.08.039

Strick, P. L., Dum, R. P., and Fiez, J. A. (2009). Cerebellum and nonmotor function. Annu. Rev. Neurosci. 32, 413-434. doi: 10.1146/annurev.neuro.31.060407.125606

Swainson, R., Rogers, R., Sahakian, B., Summers, B., Polkey, C., and Robbins, T. (2000). Probabilistic learning and reversal deficits in patients with Parkinson's disease or frontal or temporal lobe lesions: possible adverse effects of dopaminergic medication. Neuropsychologia 38, 596-612. doi: 10.1016/S00283932(99)00103-7

Taylor, A. E., and Saint-Cyr, J. A. (1995). The neuropsychology of Parkinson's disease. Brain Cogn. 28, 281-296. doi: 10.1006/brcg. 1995.1258
Taylor, A. E., Saint-Cyr, J. A., and Lang, A. E. (1986). Frontal lobe dysfunction in Parkinson's disease: the cortical focus of neostriatal outflow. Brain 109(Pt 5), 845-883. doi: 10.1093/brain/109.5.845

Thier, P., Haarmeier, T., Treue, S., and Barash, S. (1999). Absence of a common functional denominator of visual disturbances in cerebellar disease. Brain 122, 2133-2146. doi: 10.1093/brain/122.11.2133

Torta, D. M. E., Castelli, L., Zibetti, M., Lopiano, L., and Geminiani, G. (2009). On the role of dopamine replacement therapy in decision-making, working memory, and reward in Parkinson's disease: does the therapy-dose matter? Brain Cogn. 71, 84-91. doi: 10.1016/j.bandc.2009.04.003

Tremblay, P.-L., Bedard, M.-A., Langlois, D., Blanchet, P. J., Lemay, M., and Parent, M. (2010). Movement chunking during sequence learning is a dopaminedependant process: a study conducted in Parkinson's disease. Exp. Brain Res. 205, 375-385. doi: 10.1007/s00221-010-2372-6

Tzschentke, T. (2001). Pharmacology and behavioral pharmacology of the mesocortical dopamine system. Prog. Neurobiol. 63, 241-320. doi: 10.1016/S0301-0082(00)00033-2

Van Spaendonck, K. P., Berger, H. J., Horstink, M. W., Buytenhuijs, E. L., and Cools, A. R. (1996). Executive functions and disease characteristics in Parkinson's disease. Neuropsychologia 34, 617-626. doi: 10.1016/00283932(95)00159-X

von Campenhausen, S., Bornschein, B., Wick, R., Bötzel, K., Sampaio, C., Poewe, W., et al. (2005). Prevalence and incidence of Parkinson's disease in Europe. Eur. Neuropsychopharmacol. 15, 473-490. doi: 10.1016/j.euroneuro.2005.04.007

Watanabe, M., Kodama, T., and Hikosaka, K. (1997). Increase of extracellular dopamine in primate prefrontal cortex during a working memory task. J. Neurophysiol. 78, 2795-2798.

Weintraub, D., Koester, J., Potenza, M. N., Siderowf, A. D., Stacy, M., Voon, V., et al. (2010). Impulse control disorders in Parkinson disease: a cross-sectional study of 3090 patients. Arch. Neurol. 67, 589-595. doi: 10.1001/archneurol.2010.65

Williams, G. V., and Goldman-Rakic, P. S. (1995). Modulation of memory fields by dopamine $\mathrm{Dl}$ receptors in prefrontal cortex. Nature 376, 572-575. doi: $10.1038 / 376572 \mathrm{a} 0$

Wise, S. P., and Murray, E. A. (2000). Arbitrary associations between antecedents and actions. Trends Neurosci. 23, 271-276. doi: 10.1016/S0166-2236(00) 01570-8

Yarnall, A. J., Breen, D. P., Duncan, G. W., Khoo, T. K., Coleman, S. Y., Firbank, M. J., et al. (2014). Characterizing mild cognitive impairment in incident Parkinson disease The ICICLE-PD Study. Neurology 82, 308-316. doi: 10.1212/WNL.0000000000000066

Yeterian, E. H., and Pandya, D. N. (1991). Prefrontostriatal connections in relation to cortical architectonic organization in rhesus monkeys. J. Comp. Neurol. 312, 43-67. doi: 10.1002/cne.903120105

Yu, H., Sternad, D., Corcos, D. M., and Vaillancourt, D. E. (2007). Role of hyperactive cerebellum and motor cortex in Parkinson's disease. Neuroimage 35, 222-233. doi: 10.1016/j.neuroimage.2006.11.047

Ziabreva, I., Ballard, C. G., Aarsland, D., Larsen, J.-P., Mckeith, I. G., Perry, R. H., et al. (2006). Lewy body disease: thalamic cholinergic activity related to dementia and parkinsonism. Neurobiol. Aging 27, 433-438. doi: 10.1016/j.neurobiolaging.2005.02.004

Conflict of Interest Statement: The authors declare that the research was conducted in the absence of any commercial or financial relationships that could be construed as a potential conflict of interest.

Copyright (c) 2015 Hanganu, Provost and Monchi. This is an open-access article distributed under the terms of the Creative Commons Attribution License (CC BY). The use, distribution or reproduction in other forums is permitted, provided the original author(s) or licensor are credited and that the original publication in this journal is cited, in accordance with accepted academic practice. No use, distribution or reproduction is permitted which does not comply with these terms. 